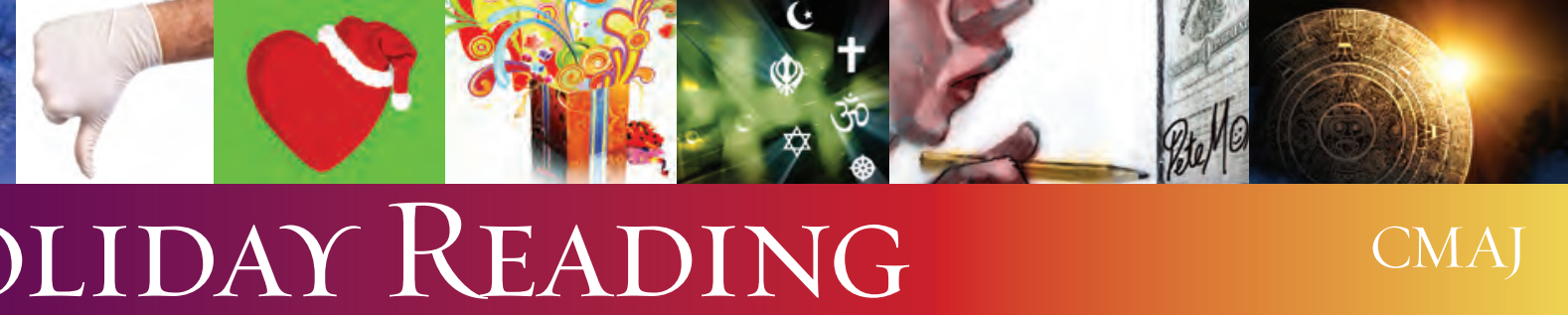

Auscultations

\title{
Technology use by physicians and their impersonators
}

\author{
Nav Persaud MD MSc
}

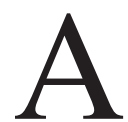

nurse first became suspicious of Ernest Addo, who had impersonated a physician while caring for more than 500 patients, when he had to use the website Ask.com to verify a management plan. ${ }^{1}$ Had Mr. Addo been a fully qualified physician, he would have just Googled it. This case illustrates how difficult it is to distinguish fake doctors from real ones based on their use of information resources.

Before doctors had rapid access to medical information using modern technology, they used Palm Pilots. And before that dark period (the "lost stylus" era), doctors had to read books. It was easier then to spot the fakes. An impersonator would have a hard time keeping up pleasant banter with a patient while thumbing through a medical dictionary for "eczema," especially if he didn't know how to spell it. Because it was impossible to keep all of the necessary books in the office, fakes had to think up increasingly implausible excuses for running to a library while a patient waited. Pulling the fire alarm worked only when done infrequently. The same went for actually setting fires.

As online resources have made it child's play to distinguish a pinguecula from a pterygium, the differences between real and fake doctors have become more subtle. Suspicious nurses have identified some general principles:

- Fake doctors have subscriptions to expensive online resources. Real doctors enroll in a series of free 30-day trials using different email addresses.

- Fake doctors use online resources to make sure they have not forgotten a rare condition in a differential diagnosis. Real doctors use them for pretty much everything.

- Fake doctors conceal their use of online resources by shutting off their monitor when colleagues approach. Real doctors access these resources openly and boast about their reliance on them.

- Fake doctors use online resources to look up drug-drug interactions. Real doctors figure drug-drug interactions are rare.

There are also some tell-tale signs in specific situations:

- Fake pediatricians use online calculators to compute the dose of medications for small children. Real pediatricians know the right dose by looking at how children fill out their clothing.

- Fake psychiatrists have to look up the diagnostic criteria for borderline personality disorder. Real psychiatrists can make the diagnosis based on the size of the patient's chart.

- Fake family physicians routinely use an online calculator based on the McIsaac Decision Rule ${ }^{2}$ to avoid inappropriate prescribing of antibiotics for sore throats. Real family physicians use the calculator only when it supports their decision.

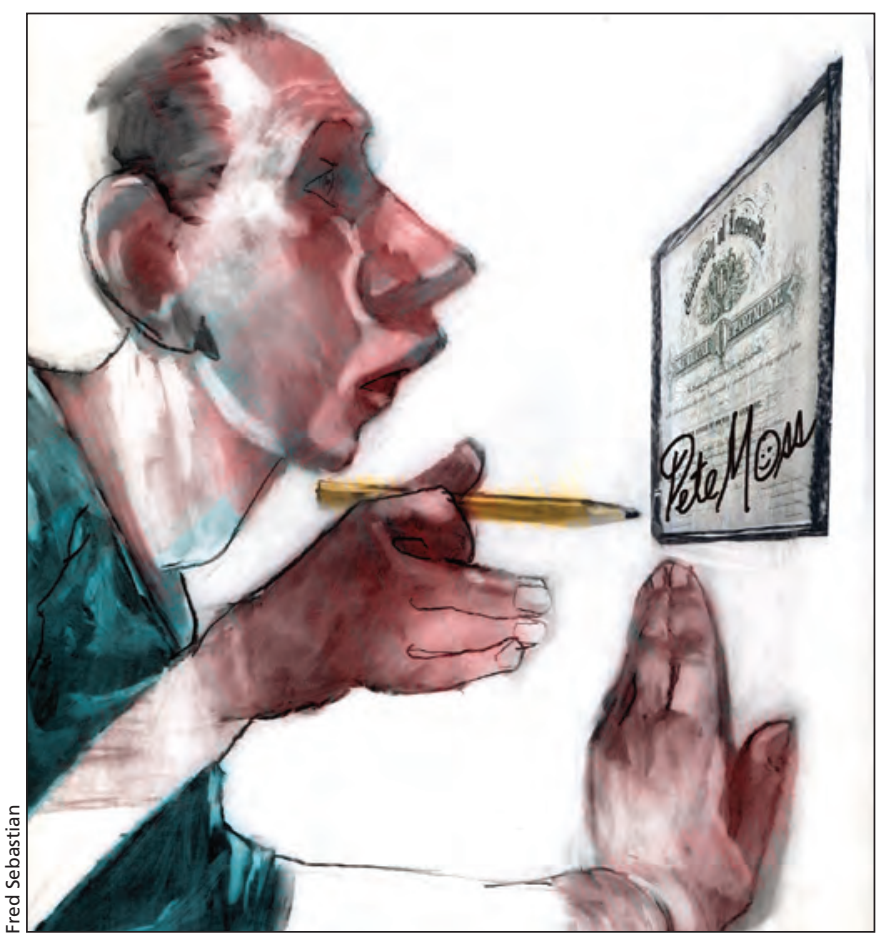

- Fake internal medicine residents have one eye on the patient and one eye on an instructional video playing on their BlackBerry when they perform a thoracentesis. Real internal medicine residents watch the video on an iPhone.

A patient recently questioned whether I was a real doctor, so I simply turned my computer screen toward him and demonstrated my facility with eMedicine. I did such a good job that he never came back.

\section{References}

1. Collins J. Man stole doctor's ID, saw 500 patients in past year; police investigating. Toronto Star 2012 Aug. 31. Available: www.thestar.com/news/world/article/1249704 -man-stole-doctor-s-id-saw-500-patients-in-past-year-police-investigating (accessed 2012 Nov. 6).

2. McIsaac WJ, White D, Tannenbaum D, et al. A clinical score to reduce unnecessary antibiotic use in patients with sore throat. CMAJ 1998;158:75-83.

\section{Correspondence to: Nav Persaud, nav.persaud@utoronto.ca}

Affiliations: Nav Persaud is with the Department of Family and Community Medicine, St. Michael's Hospital and University of Toronto, and the Keenan Research Centre in the Li Ka Shing Knowledge Institute, St. Michael's Hospital, Toronto, Ont.

CMAJ 2012. DOI:10.1503/cmaj.121664 